\title{
Posterior Retroperitoneoscopic Resection of Extra-adrenal Paraganglioma Located in the Aorto-caval Space
}

\author{
Sang-Wook Kang, MD ${ }^{1}$, Emad Kandil, MD², Min Jhi Kim, MD ${ }^{1}$, Kwang Soon Kim, MD ${ }^{1}$, Cho Rok Lee, MD ${ }^{1}$, \\ Jong Ju Jeong, MD ${ }^{1}$, Kee-Hyun Nam, MD ${ }^{1}$, Woong Youn Chung, MD $^{1}$, and Cheong Soo Park, MD ${ }^{1}$ \\ ${ }^{1}$ Department of Surgery, Yonsei University College of Medicine, Seoul, South Korea; ${ }^{2}$ Department of Surgery-Oncology, \\ Tulane University College of Medicine, New Orleans, LA
}

\begin{abstract}
Background. The posterior retroperitoneoscopic adrenalec tomy has several advantages compared with the transperitoneal approach such as a shorter and more direct route to the target organ, no breach of the intraperitoneal space, and no required retraction of the adjacent organs. It also is a safe procedure with a short learning curve.$^{1-5}$ This report presents a challenging case of an extra-adrenal paraganglioma located in the aorto-caval space and managed using the retroperitoneal approach.
\end{abstract}

Methods. A 39-year-old man was placed in the prone jackknife position, and three incisions were made in the right posterior abdominal wall for placement of the laparoscopic ports. The retroperitoneal space was entered with diathermy and blunt finger dissection, and retropneumoperitoneum was achieved with carbon dioxide insufflation pressure up to $18 \mathrm{mmHg}$. After identification of the right kidney and vessels, the tumor was meticulously dissected and excised with an energy device. The specimen was removed using a laparoscopic specimen retrieval bag, and the port sites were closed in layers.

Results. The operative time was $130 \mathrm{~min}$, and the total blood loss was $30 \mathrm{ml}$. The tumor was diagnosed as a moderately differentiated extra-adrenal paraganglioma.

Electronic supplementary material The online version of this article (https://doi.org/10.1245/s10434-017-6285-5) contains supplementary material, which is available to authorized users.

(C) Society of Surgical Oncology 2018

First Received: 25 September 2017;

Published Online: 12 January 2018

C. R. Lee, MD

e-mail: crlee@yuhs.ac
The Von Hippel-Lindau gene mutation was detected using next-generation sequencing.

Conclusions. The posterior retroperitoneoscopic approach is a safe, feasible, and effective method for excising an extra-adrenal paraganglioma even in the aorto-caval space. The authors suggest that this procedure is a useful surgical option for treatment of an aorto-caval paraganglioma for selected patients and by experienced surgeons.

\section{REFERENCES}

1. Walz MK. Minimally invasive adrenal gland surgery: transperitoneal or retroperitoneal approach? Chirurg. 2012;83:536-45.

2. Lee CR, Walz MK, Park S, et al. A comparative study of the transperitoneal and posterior retroperitoneal approaches for laparoscopic adrenalectomy for adrenal tumors. Ann Surg Oncol. 2012;19:2629-34

3. Chai YJ, Kwon H, Yu HW, et al. Systematic review of surgical approaches for adrenal tumors: lateral transperitoneal versus posterior retroperitoneal and laparoscopic versus robotic adrenalectomy. Int J Endocrinol. 2014. https://doi.org/10.1155/ 2014/918346

4. Walz MK, Metz KA, Gorges R, et al. Endoscopic excision of extra-adrenal pheochromocytomas (paragangliomas). Chirurg. 2000;71:1504-8.

5. $\mathrm{Xu} \mathrm{W,} \mathrm{Li} \mathrm{H,} \mathrm{Ji} \mathrm{Z,} \mathrm{et} \mathrm{al.} \mathrm{Comparison} \mathrm{of} \mathrm{retroperitoneoscopic} \mathrm{versus}$ transperitoneoscopic resection of retroperitoneal paraganglioma: a control study of 74 cases at a single institution. Medicine. 2015;94:e538. 